\title{
Correlation of Hepcidin to Other Markers of Iron Overload in Egyptian Thalassemia Patients
}

\author{
Rania A. Radwan, Hanan Hamed, Mariam Ahmed, Mostafa El-Razzaz \\ Internal Medicine Department, Faculty of Medicine, Ain Shams University, Cairo, Egypt \\ *Corresponding author: Mostafa Kamal El Razzaz, Mobile: 00201000459560, Email: dr.mostafa_elrazzaz@med.asu.edu.eg
}

\begin{abstract}
Background: Beta thalassemia is a disorder of hemoglobin leading to hemolytic anemia, ineffective erythropoiesis and iron overload that mediates much of the morbidity and mortality of the disease. Hepcidin is a peptide hormone that plays a crucial role in iron homeostasis. Objectives: Here we assessed the value of serum hepcidin level as a marker of iron overload in thalassemia patients. Patients and Methods: This case control study involved 30 thalassemia patients and 10 controls. The patients were selected from the Hematology Department of Ain Shams University Hospitals. We assessed the value of serum hepcidin level and see how it is correlated to values of serum ferritin along with MRI T2*on the liver and the heart in the same patients. Results: The median hepcidin level for cases was significantly lower than that for controls with $\mathrm{P}$ value (0.004), but serum hepcidin was not a statistically significant marker of iron overload when correlated with either serum ferritin or hepatic and/or cardiac MRI T2* findings of the patients. However, we found a significant correlation between hepcidin and gender, blood transfusion frequency and hepatitis $\mathrm{C}$ infection. Conclusion: hepcidin is not directly correlated to markers of iron overload in thalassemia patients. In these patients with anemia and iron overload, the erythropoietic drive is the dominant factor influencing hepcidin levels. Therefore, hepcidin is not a good marker of iron overload, but rather a good marker of erythropoietic drive.
\end{abstract}

Keywords: Hepcidin, Iron overload, Thalassemia.

\section{INTRODUCTION}

Thalassemia syndromes are a group of hereditary blood disorders characterized by reduced or absent globin chain synthesis, resulting in reduced $\mathrm{Hb}$ in red blood cells (RBC), decreased RBC production and hemolytic anemia. Most thalassemias are inherited as recessive traits (1). Thalassemia is sub-classified according to the globin chain whose production is impaired. The most clinically significant forms are those affecting the alpha globin chain (Alpha Thalassemia) and those affecting the beta globin chain (Beta Thalassemia) (2).

Beta thalassemia major patients develop iron overload with time due to blood transfusions. Even patients not on regular blood transfusions develop iron overload since the state of anemia in the body triggers increased iron absorption. In normal physiological conditions, the deleterious effects of free iron are prevented by binding iron to carriers that include transferrin. In conditions of increased iron load such as in beta thalassemia, the binding capacity of transferrin is saturated, and the remaining iron enters circulation as free iron (Non-Transferrin Bound Iron or NTBI) and exerts its harmful effects on different body tissues. NTBI is distributed and deposited in the heart, endocrine organs, and liver cells, where it causes arrhythmias, cardiomyopathy, and heart failure as well as endocrinopathies such as diabetes, hypothyroidism and hypoparathyroidism, and hepatitis, liver cirrhosis or even hepatocellular carcinoma ${ }^{(3)}$.
Hepcidin is a peptide hormone consists of 25 amino acids and is synthesized in the liver and encoded by the Hamp gene. It plays a principal role in iron homeostasis. It works on ferroportin, a transmembrane protein that is expressed in duodenal enterocytes, hepatocytes, and macrophages, which allows for absorption of iron in the intestines by enterocytes as well as export of iron out of cells. "The hepcidin-ferroportin axis" has been considered as the central player in regulating iron homeostasis (4). Hepcidin decreases serum iron by binding to iron exporter ferroportin and causing its internalization and degradation ${ }^{(5)}$.

Currently iron overload is assessed with laboratory markers such as serum ferritin and imaging studies such as MRI T2* on the liver and the heart. While these studies are important in assessment of iron overload, they are not without their drawbacks. While serum ferritin is very valuable in providing an idea about body iron stores and in following trends in body iron "Decreasing or increasing" burden, serum ferritin is not without its fallacies. It increases in many inflammatory conditions and at very high levels of body iron, serum ferritin does not follow a linear relationship with iron overload and does not reflect body iron burden well ${ }^{(6)}$.

MRI is now the most widely used technique for determining liver and heart iron concentrations. But as the MRI is not widely available and is an expensive investigation, this poses limitations to its universal application in assessing iron overload in beta thalassemia patients worldwide ${ }^{(7)}$. 
This study was designed to assess the value of serum hepcidin level as a marker of iron overload and see how it correlates to values of serum ferritin along with MRI T2*on the liver and the heart in beta thalassemia patients.

\section{PATIENTS AND METHODS}

This study involved 30 patients and 10 control adults. The patients were selected from the Hematology Department of Ain Shams University Hospital from the outpatient clinic.

Subjects with active infections or inflammatory conditions were excluded from the study to avoid rise in serum ferritin or hepcidin as part of acute phase reaction.

\section{Ethical approval:}

An approval of the study was obtained from Ain Shams University academic and ethical committee. Every patient signed an informed written consent for acceptance of the operation.

\section{Study procedures:}

The following was performed for all patients:

- Full history taking and full clinical examination.

- Lab investigations: (Liver and kidney function tests, serum ferritin, hepcidin level, HBsAg, HIV antibody and HCV antibody).

- MRI T2* on liver and heart.

Hepcidin level was assayed quantitatively using a sandwich ELISA detection kit. The sample type used was serum. The samples were collected in the early morning from $8-9: 30$ am as a pre-transfusion sample in patients presenting for blood transfusion.

\section{The procedure for obtaining hepcidin levels was as} follows:

1. Samples were collected from patients in EDTA tubes and was stored at -80 degrees Celsius (for less than 2 months) until all samples had been collected and hepcidin assay was performed.

2. Plasma was centrifuged at a speed of $2000-3000 \mathrm{rpm}$ for 20 minutes. The supernatant was removed and if precipitation appeared, it was centrifuged again.

\section{Reagent preparation:}

a. Buffer was washed once and if crystals had formed in the concentrate, the sample was heated to room temperature and mixed gently until the crystals had completely dissolved.

b. Diluted $20 \mathrm{~mL}$ of the wash buffer concentrate (20x) into distilled water to prepare $400 \mathrm{~mL}$ of wash buffer (1x)

c. Standard was diluted. Pipetted $50 \mathrm{uL}$ standard dilution in each tube. Pipetted $100 \mathrm{uL}$ in the fifth tube. Took out 100
$\mathrm{uL}$ from the fifth tube into the fourth. Pipetted $50 \mathrm{uL}$ from the fourth tube into the third tube and produced dilution series. The undiluted standard served as the high standard (180 ug) and the sample diluent served as the zero standard.

\section{Assay procedure:}

a. Pipetted standard $50 \mathrm{uL}$ to testing standard well, and pipetted $40 \mathrm{uL}$ of pipette sample dilution to testing sample well and then added testing sample $10 \mathrm{uL}$. Pipetted samples into well and mixed gently.

b. Incubation: at 37 degrees Celsius for 30 minutes.

c. Configurate liquid: diluted wash solution 20-fold with distilled water.

d. Washing: uncover the adhesive strip, discard liquid pipette washing buffer to every well, still for $30 \mathrm{~s}$ then drain and repeat 5 times.

e. Add enzyme: Pipette HRP conjugate reagent $50 \mathrm{uL}$ to each well except blank well.

f. Incubate as in step b.

g. Washing as in step d.

h. Color: pipette chromogen solution A $50 \mathrm{uL}$ and chromogen solution B to each well. Avoid the light preservation for 15 minutes at 37 degrees Celsius.

i. Stop the reaction: pipette stop solution $50 \mathrm{uL}$ to each well, stop the reaction (color changes from blue to yellow).

j. Calculate: take blank well as zero. Read absorbance at $450 \mathrm{~nm}$ after pipette stop solution within 15 minutes.

5. Calculation of result: Take the standard concentration as horizontal, the OD value for the vertical, draw the standard curve on the graph paper, find out the corresponding concentration according to the sample OD value by the sample curve, multiplied by the dilution multiple ${ }^{(5)}$.

\section{Statistical Methods}

IBM SPSS statistics (V. 24.0, IBM Corp., USA, 2016) was used for data analysis. Data were expressed as median and percentiles for quantitative non-parametric measures in addition to both number and percentage for categorized data. The following tests were done: Wilcoxon Rank Sum test, Kruskall Wallis test and Ranked Spearman correlation test. The probability of error at 0.05 was considered significant while at 0.01 and 0.001 were highly significant.

\section{RESULTS}

The present study enrolled thirty thalassemia patients with median age 30 years, 23 females (77\%) and 7 males (23\%). It also involved the recruitment of 10 controls that were healthy and matching the patients in age and sex (Figures 1,2). 


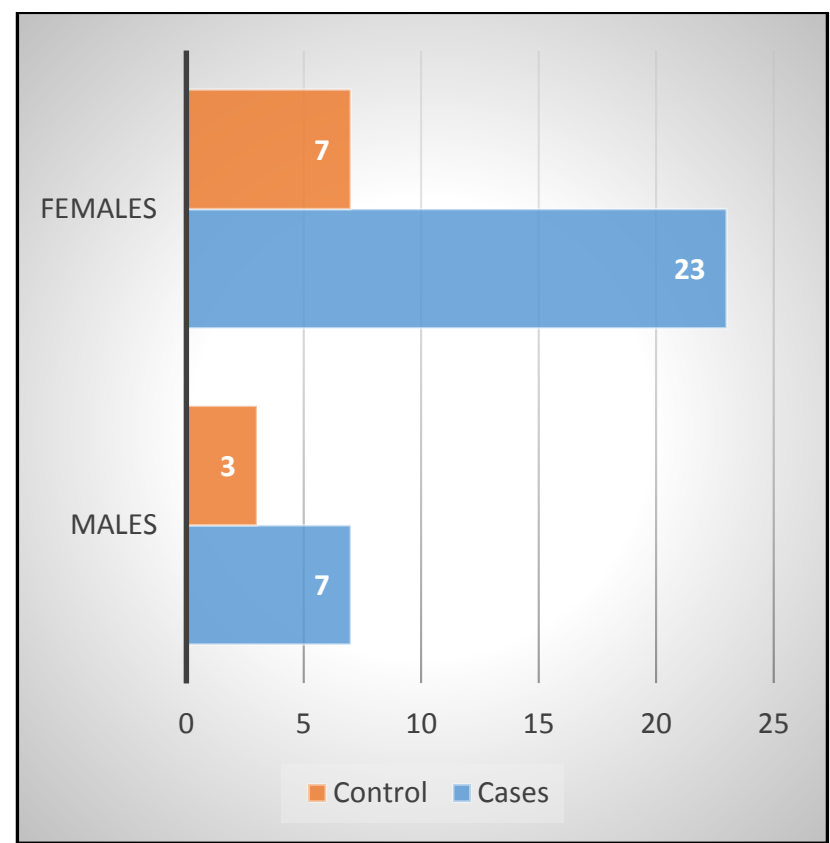

Figure (1): Sex distribution of patients and control

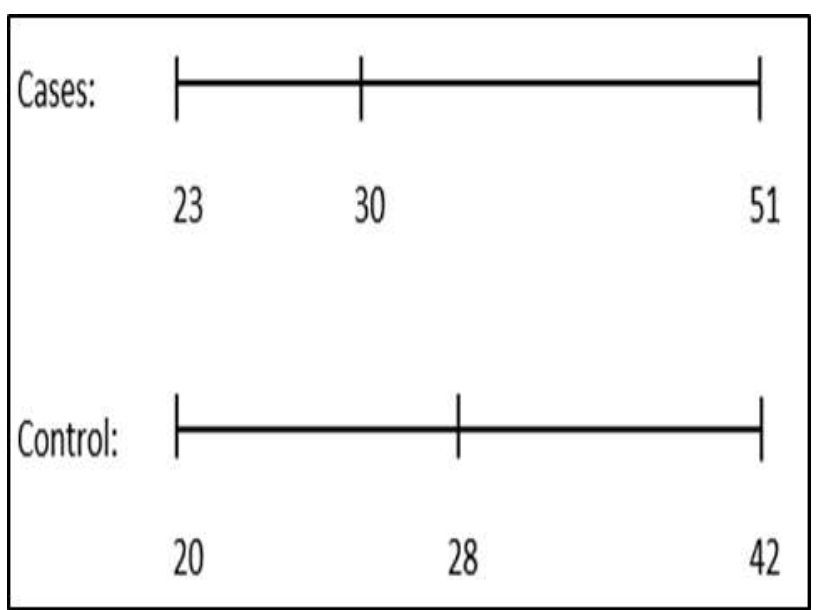

Figure (2): Age distribution of patients and control

Twenty-three patients were diagnosed as beta thalassemia intermediate $(77 \%)$ and seven were beta thalassemia major (23\%), their median hemoglobin level was $7.2 \mathrm{gm} / \mathrm{dl}$. 4 patients used combined IV and oral iron chelators while 9 patients received no chelation and the greatest fraction used single oral or IV chelator (17 out of 30). 13 patients had $\mathrm{HCV}$ infection, no patient enrolled had HBV infection and 17 patients had neither infection. The median transfusion requirement was 21 unit packed red blood cells (PRBCs)/year (Table 1).
Table (1): Descriptive data on studied patients

\begin{tabular}{|l|l|l|}
\hline \multirow{4}{*}{ Diagnosis (n, \%) } & Thalassemia major & $7(23 \%)$ \\
\cline { 2 - 3 } & $\begin{array}{l}\text { Thalassemia } \\
\text { intermediate }\end{array}$ & $23(77 \%)$ \\
\hline \multirow{4}{*}{$\begin{array}{l}\text { Chelation } \\
\text { therapy (n, \%) }\end{array}$} & $\begin{array}{l}\text { Single agent (oral } \\
\text { or IV) }\end{array}$ & $\begin{array}{l}17 \\
(56.6 \%)\end{array}$ \\
\cline { 2 - 3 } & $\begin{array}{l}\text { Combined } \\
\text { (oral+IV) }\end{array}$ & $4(13.4)$ \\
\cline { 2 - 3 } & No chelation & $9(30 \%)$ \\
\hline \multirow{4}{*}{$\begin{array}{l}\text { Viral infection } \\
\text { (n, \%) }\end{array}$} & HCV & $\begin{array}{l}13 \\
(43.4 \%)\end{array}$ \\
\cline { 2 - 3 } Splenectomy & HBV & 0 \\
\cline { 2 - 3 } & None & $17(56.6)$ \\
\hline \multirow{4}{*}{$\begin{array}{l}\text { Transfusion } \\
\text { requirements in } \\
\text { PRBCs / year }\end{array}$} & Splenectomized & $\begin{array}{l}17 \\
(56.7 \%)\end{array}$ \\
\cline { 2 - 3 } & Non & $\begin{array}{l}13 \\
(43.3 \%)\end{array}$ \\
\cline { 2 - 3 } & splenectomized & $\begin{array}{l}21 \text { units } \\
\text { /year }\end{array}$ \\
\cline { 2 - 3 } & Median PRBCs & $\begin{array}{l}15 \text { units } \\
\text { /year }\end{array}$ \\
\hline
\end{tabular}

The median level of serum ferritin was higher in patients than that in controls, while serum hepcidin was higher in controls than that in patients with highly significant difference for both (Table 2).

Table (2): Ferritin and Hepcidin levels for patients and controls

\begin{tabular}{|l|l|c|c|c|}
\hline & & Patients & Controls & P value \\
\hline \multirow{5}{*}{ Ferritin } & Median & 2000 & 77.5 & \multirow{5}{*}{ Hepcidin } \\
\cline { 2 - 4 } & $\begin{array}{l}25^{\text {th }} \\
\text { percentile }\end{array}$ & 2000 & 31 & \multirow{2}{*}{0.001} \\
\cline { 2 - 4 } & $\begin{array}{l}75^{\text {th }} \\
\text { percentile }\end{array}$ & 3057 & 138.5 & \\
\hline & $\begin{array}{l}\text { Median } \\
\text { 25 } \\
\text { percentile }\end{array}$ & 100 & 237.5 & \multirow{2}{*}{0.004} \\
\cline { 2 - 4 } & $\begin{array}{l}75^{\text {th }} \\
\text { percentile }\end{array}$ & 240 & 338 & \\
\hline
\end{tabular}

Normal ferritin level is 20-200 nanogram/L. Normal hepcidin level is $17-286$ microgram $/ \mathrm{L}$

No significant correlation could be detected on comparing serum hepcidin to MRI T2* findings of the liver and heart in thalassemia patients (Table 3 ). 
Table (3): Correlation between hepcidin and cardiac, hepatic MRI T2* findings

\begin{tabular}{|l|c|}
\hline & $\begin{array}{c}\text { P } \\
\text { Value }\end{array}$ \\
\hline $\begin{array}{l}\text { Cardiac MRI T2* on Hepcidin Levels Using } \\
\text { Wilcoxn Rank Sum Test }\end{array}$ & 0.142 \\
\hline $\begin{array}{l}\text { MRI T2* Liver Iron Concentration on } \\
\text { Hepcidin Levels Using Kruskall-Wallis Test }\end{array}$ & 0.173 \\
\hline
\end{tabular}

Correlation of serum hepcidin with frequency of blood transfusion in thalassemia patients was highly significant, while it was non-significant when correlated with serum ferritin level and hemoglobin levels (Table 4).

Table (4): Hepcidin levels in relation to variables

\begin{tabular}{|l|c|c|}
\hline & $\begin{array}{c}\text { Ratio to } \\
\text { Hepcidin }\end{array}$ & $\begin{array}{c}\text { P } \\
\text { value }\end{array}$ \\
\hline Ferritin & -0.012 & 0.236 \\
\hline PRBC & -0.529 & 0.003 \\
\hline Hemoglobin & 0.134 & 0.479 \\
\hline
\end{tabular}

Hepcidin levels were significantly lower in HCV patients with a median hepcidin of 52 micrograms/L and higher in patients without $\mathrm{HBV}$ or $\mathrm{HCV}$ with a median hepcidin of 200 micrograms/L with a $\mathrm{P}$ value of 0.005 (Figure 3).

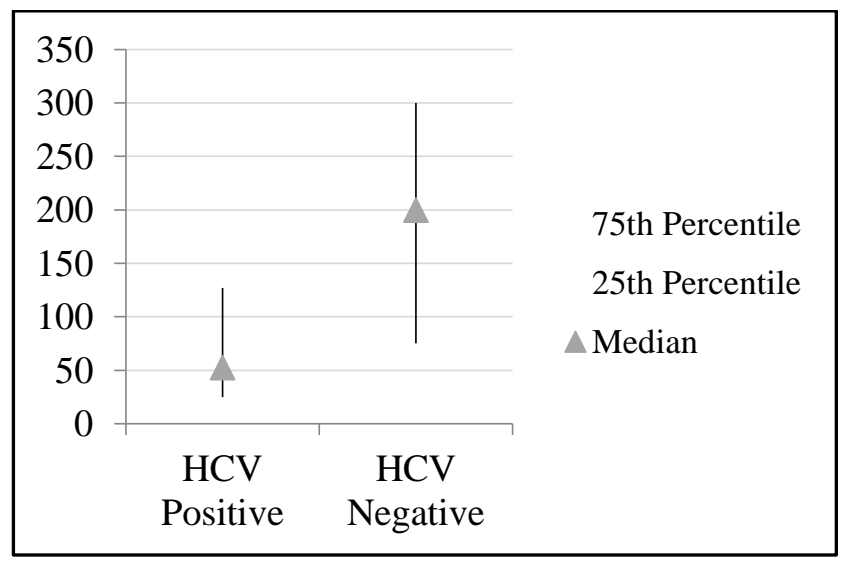

Figure (3): Effect of HCV status on hepcidin levels using Wilcoxn rank sum test

\section{DISCUSSION}

Hepcidin is the master hormone controlling iron metabolism and iron hemostasis. It is encoded by the Hamp gene and undergoes regulation by many competing factors ${ }^{(4)}$.

In this study, hepcidin level was measured in known beta thalassemia patients and correlated with several factors. The patient population included 30 patients with beta thalassemia consisted of 7 patients with thalassemia major (TM) and 23 patients with thalassemia intermediate (TI). The median age of the patients was 30 years old. Hemoglobin level in patient population ranged between 5.9-9.4 g/dl with medial level $7.2 \mathrm{~g} / \mathrm{dl}$. The studied patients were all on regular blood transfusion schedules, all were heavily iron overloaded, with the median ferritin being $2000 \mathrm{ng} / \mathrm{dL}$ and all patients showed some degree of liver iron overload according to MRI T2* findings.

Our study was designed to assess the value of hepcidin as a marker of iron overload. Hepcidin levels in patients with beta thalassemia were compared to serum ferritin levels and MRI T2* findings in the liver and heart. We found no significant correlation between hepcidin with either serum ferritin or MRI T2* findings in the liver (i.e. liver iron concentration) or in the heart (i.e. myocardial iron overload).

This is consistent with other studies that have demonstrated that hepcidin is not directly correlated to markers of iron overload in thalassemia patients. The study performed by Kattamis et al. ${ }^{(8)}$ found that hepcidin "did not correlate with indices of iron stores such as liver iron concentration (LIC) and ferritin." They went on to explain this finding by writing, "this is to be expected as it is known that regulation of iron balance according to iron stores breaks down in disorders with massive erythroid proliferation and ineffective erythropoiesis." In these states of anemia, ineffective erythropoiesis and iron overload, the upper hand in controlling hepcidin levels is erythropoietic drive ${ }^{(\mathbf{9 , 1 0})}$.

The effect of blood transfusion on hepcidin levels was found to be highly significant. This is consistent with other studies that found that more frequent blood transfusions were associated with a higher hepcidin level, while patients receiving blood transfusion less frequently or patients who were transfusion-independent had suppressed hepcidin level ${ }^{(\mathbf{9 , 1 1})}$. Origa et al. ${ }^{\left({ }^{(1)}\right)}$ states that frequent blood transfusions suppress erythropoietic drive and consequently lead to higher hepcidin level. Likewise, anemia is also correlated to hepcidin level through erythropoietic drive that increases with increasing anemia.

In our study hepcidin levels were significantly lower in HCV infected patients compared to HCV negative patients. In the study performed by Origa $\boldsymbol{e t}$ al. (11) where the authors noted that HCV was a "confounding factor" in the study and determined that since all patients had normal liver transaminases and no evidence of cirrhosis, therefore the effect of $\mathrm{HCV}$ on hepcidin may be minimal.

A study performed by Armitage et al. ${ }^{(12)}$ on $\mathrm{HCV}$ patients (on a patient population that did not include beta thalassemia patients) found that hepcidin levels are not increased in the acute viral infection with $\mathrm{HCV}$ as may be hypothesized due to its role as an acute phase reactant. 
The study also found that "hepcidin is suppressed during chronic HCV". However, this study included only 10 patients with $\mathrm{HCV}$, therefore the small patient size warrants further study to confirm these findings.

Another study performed by Girelli et al. (13) compared serum hepcidin levels in 81 patients with chronic hepatitis $\mathrm{C}$ infection without specific treatment compared to 47 controls. The study found that hepcidin levels were significantly lower in patients with chronic hepatitis $\mathrm{C}$ in comparison to controls with a $\mathrm{p}$ value of $<0.001$. This is consistent with the results of our study. However, they wrote that "using gender-matched controls, we unequivocally demonstrated that $\mathrm{CHC}$ [chronic hepatitis C] hepcidin concentrations are significantly lower than those of matched controls. Hepcidin downregulation is likely to contribute to liver iron accumulation in this condition".

\section{CONCLUSION}

Our study found that in patients with anemia and iron overload, such as beta thalassemia patients, serum hepcidin level is not a statistically significant marker of iron overload and the erythropoietic drive is the dominant factor influencing hepcidin levels.

Future studies may be needed to help elucidate more about hepcidin, its regulation, and its potential role as a diagnostic tool.

\section{REFERENCES}

1. Origa R, Moi $P$ (2005): Alpha thalassaemia. In GeneReviews ${ }^{\circledR}[$ Internet]; Adam, M.P., Ardinger, H.H., Pagon, R.A., Wallace, S.E., Bean, L.J.H., Stephens, K., Amemiya, A., Eds.; University of Washington, Seattle: Seattle, WA, USA, Pp. 1-30.

2. Forget B, Bunn H (2013): Classification of the disorders of hemoglobin. Cold Spring Harb Perspect Med., 3(2): 11684-89.
3. Bayanzay K, Alzoebie L (2016): Reducing the iron burden and improving survival in transfusion-dependent thalassemia patients: current perspectives. J Blood Med., 7:159-69.

4. Liu J, Sun B, Yin H et al. (2016): Hepcidin: A promising therapeutic target for iron disorders: A systematic review. Medicine (Baltimore), 95(14): 3150-55.

5. Chifman J, Laubenbacher R, Torti $S$ (2014): A systems biology approach to iron metabolism. Adv Exp Med Biol., 844:201-25.

6. Cappellini M, Cohen A, Porter J et al. (2014): Guidelines for the management of transfusion dependent thalassaemia $\begin{array}{llll}\text { (TDT). Nicosia } & \text { (CY), } & \text { Pp. } & \text { 1-253. }\end{array}$ https://thalassaemia.org.cy/wpcontent/uploads/2017/08/GuidelinesTDT_English.pdf

7. Westwood M, Firmin D, Gildo $M$ et al. (2005): Intercentre reproducibility of magnetic resonance $\mathrm{T} 2 *$ measurements of myocardial iron in thalassaemia. Int $\mathrm{J}$ Cardiovasc Imaging, 21(5):531-8.

8. Kattamis A, Papassotiriou I, Palaiologou D et al. (2006): The effects of erythropoetic activity and iron burden on hepcidin expression in patients with thalassemia major. Haematologica, 91(6):809-12.

9. Haghpanah S, Esmaeilzadeh M, Honar N et al. (2015): Relationship between serum hepcidin and ferritin levels in patients with thalassemia major and intermedia in Southern Iran. Iran Red Crescent Med J., 17: 28343-49.

10. Pasricha S, Frazer D, Bowden D et al. (2013): Transfusion suppresses erythropoiesis and increases hepcidin in adult patients with beta-thalassemia major: a longitudinal study. Blood, 122(1):124-33.

11. Origa R, Galanello R, Ganz $T$ et al. (2007): Liver iron concentrations and urinary hepcidin in beta-thalassemia. Haematologica, 92(5):583-8.

12. Armitage A, Stacey A, Giannoulatou E et al. (2014): Distinct patterns of hepcidin and iron regulation during HIV-1, HBV, and HCV infections. Proc Natl Acad Sci USA., 111(33):12187-92.

13. Girelli D, Pasino M, Goodnough J et al. (2009): Reduced serum hepcidin levels in patients with chronic hepatitis C. J Hepatol., 51(5):845-52. 